\title{
Performance of Male Midwives in the different Hospitals and Clinics in Kalinga
}

\section{Isaiah G. Patong}

\author{
Kalinga State University, Philippines
}

Received: 08 Oct 2020; Received in revised form: 20 Dec 2020; Accepted: 27 Dec 2020; Available online: 31 Dec 2020 C2020 The Author(s). Published by Infogain Publication. This is an open access article under the CC BY license (https://creativecommons.org/licenses/by/4.0/).

\begin{abstract}
This study was conducted to assess male midwives' performance in the different hospitals and clinics in Kalinga. Purposive sampling technique was used in this study because only male midwives, a graduate of a two-year diploma course of midwifery, registered and employed in the six health care facilities in Kalinga were the respondents. Predisposing factors such as demographic profiles, including the respondent's Age, Civil Status, Employment Status, Length of Service, Number of Training, Hospital or Clinic Affiliation, and Classification, were considered the use of a Close and Open-Ended Questionnaire.

From the results gathered, the respondents show that their performances were excellently on the five categories, which include Ante-natal care, Intra-natal care, Post-natal care, Immunization, and Family planning. Likewise, the nine factors enumerated in the study could not affect delivering quality maternal and child care.

Therefore, it is recommended that the government, the health administrators, should work jointly to create harmonious healthcare provider-patient relationship for better health and healthy babies.
\end{abstract}

Keywords-Male Midwives, Hospitals, Clinics.

\section{INTRODUCTION}

Many women worldwide give birth when the period around birth constitutes a severe gap of opportunity to prevent and manage maternal and new-born complications. It was estimated that in 2015, pregnancy-related deaths and diseases remain unacceptably high. It also estimated that 303,000 women died from pregnancy-related causes, 2.7 million babies died during the first 28 days of life and 2.6 million babies were stillborn. However, globally, only $64 \%$ of women receive antenatal care four or more times throughout their pregnancy (World Health Organization, 2015).

Relative to it, the availability and accessibility of skilled birth attendants like midwives can help prevent complications and postnatal mortality. Without medical assistance, there could be a massively increased risk of complications or death.

Midwives are specialists in normal pregnancy and birth. Their role is to look after a pregnant woman and her baby throughout a phase of antenatal care, during labor and delivery, and up to 28 days after the baby was born. They provide all necessary professional care and services during normal pregnancy and childbirth.

The midwife's professional role has evolved to keep pace with the changing needs of society. The philosophy of the midwife's role sits within the paradigm of standard midwifery care during the antenatal, intra-natal, and postnatal periods.

According to late Ms. Alice Dela Gente, former president of the Integrated Midwives Association of the Philippines (IMAP), in early 2008, there were 50,722 registered midwives as of June 2007, and there were 3,498 newly registered midwives in 2007. Midwives work in the private or public sector in hospitals, birthing clinics, barangay (village) health stations, or rural health units--or they work abroad. They comprise $65 \%$ of the public health workforce. In rural areas, they are the first point of contact for patients coming into the health system. In 2005, 16,967 government midwives 
delivered frontline services in 15,436 barangay health stations and 2266 rural health units (Philippines House Bill Number 2673).

The performance of midwives needs to be assessed because skilled birth attendants are widely recognized as critical factors in reducing maternal and newborn mortality. The competence of maternal healthcare providers directly affects the quality of care and health outcomes.

Over time, nursing and midwifery evolved to include males. It was found out in the study of Evans 2002 that men gradually began challenging the notion that they were inappropriate in caregiving roles or incapable of providing sensitive and compassionate care. Gender stereotyping created complex situations of acceptance, rejection, and suspicion of men as nurturers and caregivers.

In connection to this, clinics and hospitals in Kalinga, where male midwives were employed, experienced job discrimination. Instead of practicing their profession, the male midwives could not exercise their job due to negative notions from the people around them that female midwives perform well..

Concerning this, the study aimed to determine male midwives' performance in the different hospitals and clinics in Kalinga. This study's results would be an instrument as an eye-opener to the public that an individual's biological sex cannot affect one's performance in delivering quality services.

\section{METHODOLOGY}

The researcher used the descriptive survey method as the most appropriate method for the study. According to Adanza, Bermundo, and Rasonabe (2010), it is designed to gather information about the present conditions, status or trend, and dealing with what is prevailing. The study's main objective is to describe the nature of a situation as it exists at the time of the research and to explore the causes of a particular phenomenon. The study was conducted in the different hospitals and clinics in Kalinga, namely Juan M. Duyan Memorial Hospital, Saint Peter Claver Hospital, JVA Hospital, RHU 1-Tabuk, RHU-Tanudan, and PSALMS 91 Birthing Clinic. Furthermore, the study was conducted during June 1-December 2019. The descriptive method is appropriate for the study because it needs to determine male midwives' performance in the hospitals/clinics in Kalinga. A purposive sampling design was used in the study. Only 21 male midwives, a graduate of 2-years Diploma in Midwifery, registered, and employed will be the respondents.

ISSN : 2456-7620
Participation in the survey was voluntary, and the respondents informed about the objectives of the study. The six supervisors of the six health care facilities will also be included as the supervisor's response to the factors that affect the male midwives' performance in their hospital/clinic will be gathered from them. The demographic profiles of the supervisors were not included in the study. To assess the respondents' performance in the different hospitals and clinics in Kalinga, a 5-point Likert scale was adapted; interpretation was included in the instrument. In this study, the researcher refers to some questions in the World Health Organization. Since some of the questionnaire's parameters were not appropriate or relevant to the study's locale and respondents, the researcher chose to alter and eliminate some of the questions.

A permission letter was given to the hospital/clinic administrators, particularly to the Labor and Delivery Department of hospitals and Rural Health Units. Upon approval, the researcher personally administered and collected the questionnaires to ensure the respondents' validity, reliability, and confidentiality. The face-to-face interview also conducted in a place comfortable and convenient for the participants. After retrieval of the questionnaire, the data encoded and computed in Microsoft excel. Then the results of the respondents' demographic profiles were expressed in frequency and percentage. Lastly, the mean also computed to assess male midwives' performance in the different hospitals and clinics in Kalinga and the factors that affect male midwives' performance as perceived by their immediate supervisors.

\section{RESULTS AND DISCUSSION}

Table 1 shows that most of the respondents' age range falls under 28-32, with a percentage of $38.10 \%$. Most of the respondents were single, having a rate of $80.95 \%$; this shows that male midwives do not like earlier settlement because of their young age and employment stability. Most of them were under casual or contractual employees, with a percentage of $52.38 \%$. When it comes to the length of service, most of them stayed in hospitals or clinics within 2-6 years, representing $47.61 \%$. Furthermore, most of the respondents have attended more than five training, with a percentage of $66.67 \%$. This implies that male midwives are equipping with enough knowledge when it comes to their profession.

Additionally, most of the respondents were affiliated with RHU Tabuk, representing 38.10\%. In connection to this, most 
of them connected in the government with a percentage of $61.90 \%$. Thus, the male midwives prefer to work in government institution due to the benefits they receive, and another reason is the lack of birthing facilities that is why RHU prefer to hire more midwives to cater the needs of the pregnant women and to reduce the neonatal-maternal mortality.

Table 1: Frequency and Percentage Distribution of the Respondents Demographic Profile

\begin{tabular}{|c|c|c|}
\hline $\begin{array}{l}\text { DEMOGRAPHIC } \\
\text { PROFILE }\end{array}$ & FREQUENCY & PERCENTAGE \\
\hline \multicolumn{3}{|l|}{ Age } \\
\hline $18-22$ & 2 & $9.52 \%$ \\
\hline $23-27$ & 6 & $28.57 \%$ \\
\hline $28-32$ & 8 & $38.10 \%$ \\
\hline $33-37$ & 2 & $9.52 \%$ \\
\hline $38-42$ & 3 & $14.28 \%$ \\
\hline \multicolumn{3}{|l|}{ Civil Status } \\
\hline Married & 3 & $14.27 \%$ \\
\hline Single & 17 & $80.95 \%$ \\
\hline Separated & 1 & $4.76 \%$ \\
\hline Widowed & 0 & $0 \% 4$ \\
\hline \multicolumn{3}{|l|}{ Employment Status } \\
\hline Permanent & 10 & $47.62 \%$ \\
\hline Casual/Contractual & 11 & $52.38 \%$ \\
\hline \multicolumn{3}{|l|}{ Length of Service } \\
\hline Less than 2 years & 5 & $23.81 \%$ \\
\hline $2-5$ years & 10 & $47.62 \%$ \\
\hline $6-10$ years & 3 & $14.29 \%$ \\
\hline 11 and above & 3 & $14.29 \%$ \\
\hline \multicolumn{3}{|l|}{ Number of } \\
\hline$\underline{\text { Training }}$ & 0 & $0 \%$ \\
\hline No training & 2 & $9.52 \%$ \\
\hline $1-2$ training & 4 & $19.02 \%$ \\
\hline 3-4 training & 14 & $66.67 \%$ \\
\hline More than 5 & & \\
\hline$\frac{\text { Hospital/Clinic }}{\text { Affiliation }}$ & & \\
\hline
\end{tabular}

\begin{tabular}{|c|c|c|}
\hline SPCH & 4 & $19.05 \%$ \\
JVA & 3 & $14.29 \%$ \\
JMDMDH & 2 & $9.52 \%$ \\
RHU Tanudan & 2 & $9.52 \%$ \\
RHU Tabuk & 8 & $38.10 \%$ \\
Psalms 91 & 1 & $4.76 \%$ \\
\hline$\frac{\text { Hospital/Clinic }}{\text { Classification }}$ & 8 & $38.10 \%$ \\
Private & 13 & $61.90 \%$ \\
Government & & \\
\hline
\end{tabular}

Table 2.1 shows that most of the respondents performed excellently on antenatal care with the highest mean score of 4.75 on recognizing and managing pregnancy-related complications. Followed by preventive measures, including tetanus toxoid immunization, deworming, iron, folic acid, intermittent preventive treatment of malaria in pregnancy (IPTp), insecticide-treated bed nets (ITN) with a mean score of 4.65. Then, the pregnant woman's identification and surveillance and her expected child garnered a third highest mean score of 4.60. Both indicators with the same mean score of 4.50 were recognizing and treating underlying or concurrent illness and screening for conditions and diseases such as anemia, STIs (particularly syphilis), HIV infection, mental health problems, or symptoms of stress or domestic violence. Furthermore, the lowest mean score of 4.30 was the advice and support to the woman and her family for developing healthy home behaviors and a birth and emergency preparedness plan.

Generally, it could be seen that male midwives' performance on antenatal care was excellent, with a categorical mean of 4.55. Therefore, this shows that the male midwives considered these very important to give pregnant mothers and their babies the right care. According to the World Health Organization (2016), pregnant women should receive good quality care throughout their pregnancy. The study of Hijazi (2018) suggests that the degree to which women feel respected, informed, and engaged in their care has potentially favorable antenatal care implications. Its goal is to provide regular check-ups that allow doctors or midwives to treat and prevent potential problems throughout the pregnancy and promote healthy lifestyles and benefit both mother and child. 
Table 2: Mean of the Performance of Male Midwives in the Different Hospitals and Clinics in Kalinga

\begin{tabular}{|l|c|c|c|}
\hline \multicolumn{1}{|c|}{ 2.1 Indicators on Antenatal Care } & Mean & Description & Interpretation \\
\hline $\begin{array}{l}\text { 1. Identifying and surveying a pregnant woman and her expected } \\
\text { child. }\end{array}$ & 4.60 & Excellent & Very Important \\
\hline 2. Recognizing and managing pregnancy-related complications & 4.75 & Excellent & Very Important \\
\hline 3. Recognizing and treating underlying or concurrent illness. & 4.50 & Excellent & Very Important \\
\hline $\begin{array}{l}\text { 4. Screening for conditions and diseases such as anemia, STIs } \\
\text { (particularly syphilis), HIV infection, mental health problems, or } \\
\text { symptoms of stress or domestic violence. }\end{array}$ & 4.50 & Excellent & Very Important \\
\hline $\begin{array}{l}\text { 5. Administer preventive measures, including tetanus toxoid } \\
\text { immunization, deworming, iron, folic acid, intermittent preventive } \\
\text { treatment of malaria in pregnancy (IPTp), insecticide-treated bed } \\
\text { nets (ITN). }\end{array}$ & 4.65 & Excellent & Very Important \\
\hline $\begin{array}{l}\text { 6. Advise and support the woman and her family for developing } \\
\text { healthy home behaviors and birth and } \\
\text { emergency preparedness plan. }\end{array}$ & 4.30 & Excellent & Very Important \\
\hline \multicolumn{1}{|c|}{ Categorical Mean } & $\mathbf{4 . 5 5}$ & Excellent & $\begin{array}{c}\text { Very } \\
\text { Important }\end{array}$ \\
\hline
\end{tabular}

Table 2.2 shows that most of the respondents' performed excellently on all intra-natal care indicators with the highest mean score of 4.90 regarding ensuring that the delivery room is readied. The next second-highest mean score was 4.70 derived from indicators on conduct a routine examination and measure or estimate and record blood loss. Furthermore, the third has the highest mean score of 4.65 , where the indicators check the contents of the delivery pack and inspect the placenta and membranes for completeness. The fourth highest means scores of 4.60 garnered from the indicators on review notes to identify any significant points in the history and repair episiotomy or lacerations. The fifth highest mean score derived on the indicator inspect the vagina and cervix for lacerations. The six highest mean score representing 4.50 were indicators of keeping accurate and up to date record, Watching for signs of placental separation, and cleaning perineum. The seven highest mean score of 4.45 was indicator to assist the mother in expelling the placenta. Lastly, the lowest mean score of 4.35 is on assessing the general condition and ensure that client is in labor.

Male midwives' overall performance on intra-natal care with a categorical mean of 4.43 was also an excellent job. This shows that intra-natal care is very important primarily to bring the mother into the prevention care cycle as early as possible. Highly intra-natal care is a crucial way to reduce the maternal and mortality rate of child and mothers. This means that care should be taken during delivery, not only the mother but also the newborn at the time of childbirth. This validates the findings of Bhimani (2017) that appropriate delivery care is crucial for both maternal and perinatal health. Increasing skilled attendance at birth is a central goal of the safe motherhood and child survival mission.

\begin{tabular}{|l|c|c|c|}
\hline \multicolumn{1}{|c|}{ 2.2 Indicators on Intra-natal Care } & Mean & Description & Interpretation \\
\hline $\begin{array}{l}\text { 1. Assess the general condition and ensure that client } \\
\text { is in labor. }\end{array}$ & 4.35 & Excellent & Very Important \\
\hline $\begin{array}{l}\text { 2. Review notes to identify any significant points in } \\
\text { history. }\end{array}$ & 4.60 & Excellent & Very Important \\
\hline
\end{tabular}




\begin{tabular}{|l|c|c|c|}
\hline 3. Conduct a routine examination. & 4.70 & Excellent & Very Important \\
\hline 4. Keep an accurate and up-to-date record. & 4.50 & Excellent & Very Important \\
\hline 5. Ensure that the delivery room is readied. & 4.90 & Excellent & Very Important \\
\hline 6. Check the contents of the delivery pack. & 4.65 & Excellent & Very Important \\
\hline 7. Watch for signs of placental separation. & 4.5 & Excellent & Very Important \\
\hline 8. Assist mother to expel the placenta. & 4.45 & Excellent & Very Important \\
\hline 9. Inspect placenta and membranes for completeness. & 4.65 & Excellent & Very Important \\
\hline 10. Measure or estimate and record blood loss. & 4.7 & Excellent & Very Important \\
\hline 11. Inspect the vagina and cervix for lacerations. & 4.55 & Excellent & Very Important \\
\hline 12. Repair episiotomy or lacerations. & 4.6 & Excellent & Very Important \\
\hline 13. Clean perineum. & 4.5 & Excellent & Very Important \\
\hline Categorical Mean & 4.59 & Excellent & Very Important \\
\hline
\end{tabular}

Table 2.3 shows that most of the respondents' responses on the postnatal indicators were excellent with highest mean scores of 4.75 to both indicators 3 and 4 in providing information on postnatal care and danger signs in the new mother and baby and tailoring the specific needs of the depressed postnatal woman and followed by a mean score of 4.45 in the indicator on facilitating family and group support of women - the lowest mean score of 4.35 in the indicators on postnatal care respects women's concerns.

The categorical mean score of postnatal male midwives' indicators was 4.57, meaning it also yields excellent performance. Thus, postnatal care was also indeed very important to maternal healthcare. Based on the World Health Organization, the post natal period is a critical phase in mothers and newborn babies' lives. Most maternal and infant deaths occur during this time. Yet, this is the most neglected period for the provision of quality care. Because some women will give birth in the home with a skilled attendant, others may not; that is why WHO recommends that a woman not be discharged before 24 hours after delivery. Regardless of birth, someone must accompany the woman and newborn due to possible complications that occur in the first 24 hours.

\begin{tabular}{|l|c|c|c|}
\hline 2.3 Indicators on Postnatal Care & Mean & Description & Interpretation \\
\hline $\begin{array}{l}\text { 1. Facilitate family and group support of } \\
\text { women }\end{array}$ & 4.45 & Excellent & Very Important \\
\hline 2. Respects the concerns of women & 4.35 & Excellent & Very Important \\
\hline $\begin{array}{l}\text { 3. Provide information on postnatal care and } \\
\text { danger signs in the new mother and baby }\end{array}$ & 4.75 & Excellent & Very Important \\
\hline $\begin{array}{l}\text { 4. Tailor the specific needs of the depressed } \\
\text { postnatal woman. }\end{array}$ & 4.75 & Excellent & Very Important \\
\hline Categorical Mean & $\mathbf{4 . 5 7}$ & Excellent & Very Important \\
\hline
\end{tabular}

As shown in table 2.4, most of the respondents' performance on immunization was also excellent, with the highest mean scores of 4.60 to both indicators on dosage measurement and chart monitoring. Indicator with the lowest mean score on immunization derives a 4.55 on weighing babies.

Thus, the categorical mean score of 4.58 was also excellent, giving the impression that immunization is 
essential. Therefore, immunization is very important to protect babies against different diseases especially from birth. That is why immunization especially children matters. According to the World Health Organization, immunization is a proven way to prevent and eliminate life-threatening infectious diseases worldwide. A person that has been vaccinated becomes immune or resistant to infectious disease because vaccines stimulate the body's immune system to give optimal protection against infections.

As it prevents disease, disability, and deaths, immunization also contributes to economic growth. During outbreaks, the public health system spends time tracing potential contacts, collecting and testing blood samples, engaging the public for awareness and dissemination of information, and organizing outbreak response and money for hospital treatments. Immunization helps remove the health system's burden and, most significantly, from families' most impoverished.

Infants are particularly vulnerable to infectious disease; that's why it's critical to protect them through immunization to give a healthy start into life.

\begin{tabular}{|l|c|c|c|}
\hline 2.4 Indicators on Immunization & Mean & Description & Interpretation \\
\hline 1. Dosage measurement. & 4.60 & Excellent & Very Important \\
\hline 2. Weighing Babies. & 4.55 & Excellent & Very Important \\
\hline 3. Chart Monitoring. & 4.60 & Excellent & Very Important \\
\hline Categorical Mean & $\mathbf{4 . 5 8}$ & Excellent & Very Important \\
\hline
\end{tabular}

Table 2.5 shows male midwives' performance on family planning with only two indicators having the highest mean score of 4.45 on contraceptives and lowest with a mean score of 4.40 on menstrual monitoring.

The categorical mean of the two indicators was 4.43, showing excellent family planning performance; thus, this implies that family planning is essential for couples. According to the Philippine Statistics Authority, women in low households are less likely to practice family planning, and half of the Filipino women practicing family planning. In connection to this, the World Health Organization emphasizes that family planning is essential and widely available, and easily accessible through midwives and other trained health workers. Midwives are trained to provide locally available and culturally acceptable contraceptive methods. Family planning enables people to make informed choices about their sexual and reproductive health and reduce neonatal-maternal morbidity and mortality.

\begin{tabular}{|l|c|c|c|}
\hline 2.5 Indicators on Family Planning & Mean & Description & Interpretation \\
\hline 1. Use of Contraceptives. & 4.45 & Excellent & Very Important \\
\hline 2. Menstrual Monitoring. & 4.40 & Excellent & Very Important \\
\hline Categorical Mean & $\mathbf{4 . 4 3}$ & Excellent & Very Important \\
\hline
\end{tabular}

Table 2.6 shows the summary of the five categories' categorical mean on male midwives' performance in the different clinics and hospitals in Kalinga, such as antenatal care, intra-natal care, postnatal care, immunization, and family planning. The intra-natal care indicators derived the highest categorical mean score of 4.59 among the rest of the categories. The second highest categorical mean score of 4.58 was the immunization indicators. The postnatal indicators with the third-highest categorical mean score of 4.57 and the fourth highest with a categorical mean score of 4.55 were the antenatal care indicators. Lastly, a categorical mean score of 4.43 on family planning was gathered with the lowest score.

Generally, the overall categorical mean score of the five categories on male midwives' performance was 4.54. Therefore, this shows that the male midwives' performance performed excellently because handling a child and mother's needs is very important in delivering quality health care. This finding validated the study conducted by Goshu 2018 that improved performances were associated with midwives' competence in the provision of care during labor, childbirth, and the immediate postpartum period. 


\begin{tabular}{|l|r|r|l|}
\hline $\begin{array}{l}\text { 2.6 Summary of the five Categorical Mean of } \\
\text { the Performance Indicators }\end{array}$ & Mean & Description & Interpretation \\
\hline 1. Categorical Mean of Antenatal Care Indicators & 4.55 & Excellent & Very Important \\
\hline 2. Categorical Mean of Intra-natal Care Indicators & 4.59 & Excellent & Very Important \\
\hline 3. Categorical Mean of Postnatal Care Indicators & 4.57 & Excellent & Very Important \\
\hline 4. Categorical Mean of Immunization Indicators & 4.58 & Excellent & Very Important \\
\hline 5. Categorical Mean of Family Planning Indicators & 4.43 & Excellent & Very Important \\
\hline Overall Categorical Mean & $\mathbf{4 . 5 4}$ & Excellent & Very Important \\
\hline
\end{tabular}

Table 3.0 shows the nine factors that affect male midwives' performance as perceived by their immediate supervisors. Most of the respondents answered that they were strongly disagreed that the relationship of employee and supervisor/ employer (1.05), salary and benefits (1.40), the preference among expectant mothers (1.40), tools and equipment (1.65), and burnout (1.25) affects the performance of male midwives. Thus, this is very untrue that these factors can't affect their excellent performance in delivering quality child and maternal health care services. These attitudes should always be sustaining to give the best quality maternal services among expectant mothers and reduce the rate of neonatal and maternal morbidity and mortality.

Furthermore, the rest of the response of most respondents was that they disagreed that suspicion on men's motive (1.95), technical training (2.0), job satisfaction (1.95), and client feedback (2.05) couldn't affect their performance. So, it is somewhat untrue that these factors hamper their outstanding performance on bringing quality maternal healthcare services to both child and mother health.
Overall, the categorical mean is derived from a score of 1.63 . They were strongly disagreeing that these nine factors had a significant impact on their job performance on delivering quality neonatal-maternal care.

In contrast to the results of this study, job performance is the general attitude people have about their jobs. Job factors such as the pay, the employment itself, promotion opportunities, support from supervisors, and relationships with co-workers can affect employee satisfaction. (Ahmad et al., 2002). According to a recent JobStreet.com survey conducted in September 2012 on Employee Job Satisfaction in Malaysia, $78 \%$ of the respondents claimed that they were unhappy with their current job. Dissatisfaction with their work scope was the top reason many felt unhappy at work (Daily Express, 2012). Job dissatisfied employee is most likely to show poor performance at work which indirectly affects the organization's productivity. Organizational commitment and employee job involvement will also be a question mark if the employee is not satisfied with his job.

Table 3: Mean of the Factors that Affect the Performance of Male Midwives as Perceived by their Immediate Supervisors

\begin{tabular}{|l|c|c|c|}
\hline \multicolumn{1}{|c|}{ Factors } & Mean & Description & Interpretation \\
\hline 1. Relationship of employee and supervisor/ employer. & 1.05 & Strongly Disagree & Very Untrue \\
\hline 2. Salary and benefits. & 1.4 & Strongly Disagree & Very Untrue \\
\hline 3. Preference among expectant mothers. & 1.4 & Strongly Disagree & Very Untrue \\
\hline 4. Suspicion of men's motive. & 1.95 & Disagree & Somewhat Untrue \\
\hline 5. Technical training. & 2.0 & Disagree & Somewhat Untrue \\
\hline 6. Tools and equipment. & 1.65 & Strongly Disagree & Very Untrue \\
\hline 7. Job satisfaction. & 1.95 & Disagree & Somewhat Untrue \\
\hline 8. Client feedback. & 2.05 & Disagree & Somewhat Untrue \\
\hline 9. Burnout & 1.25 & Strongly Disagree & Very Untrue \\
\hline Categorical Mean & 1.63 & Strongly Disagree & Very Untrue \\
\hline
\end{tabular}




\section{CONCLUSION}

This study shows that male midwives' performance in different hospitals and clinics in Kalinga was excellent because they excel in the five categories of neonatal-maternal care. Likewise, the male midwives prove that despite their biological sex, this couldn't affect their performance to deliver the best quality services concerning neonatal-maternal healthcare.

\section{RECOMMENDATIONS}

Based on the findings and conclusions presented, the researcher had arrived at the following recommendations:

1. The head of the health care facilities should begin basic policies on sex discrimination and include it in their advocacy on the Gender Equality Plan.

2. Health Administrators should focus on achieving goals, monitoring performance, and evaluating outcomes thru engaging them, enhance their social responsibility goals and increase productivity by sending them training suited to them.

3. Head of Human Resources should observe proper hiring male applicants, especially midwives, that their job description and job specification should be practiced and aligned with their field of expertise.

4. Competence-based in-service training, on-the-job mentoring, availability of up-to-date standard job aids, and recognition of high-performing midwives are recommended to improve maternity care quality in the public health facilities region.

5. It is recommended that health education activities on midwifery be developed to promote, improve, and sustain midwives' excellent performance to deliver quality child care and maternal care and reduce the problems of maternal issues.

Generally, it is recommended that the healthcare facilities' government head work jointly to create harmonious healthcare provider-patient relationships for better health and healthy babies.

\section{REFERENCES}

[1] Assessing the competence of midwives to provide care during labor, childbirth, and the immediate postpartum period-A cross sectional study in Tigray region, Ethiopia
[2] Donnison, J. 1988. Midwives and medical men: a history of the struggle for control of childbirth. London: Historical Publications.

[3] Goshu M, Godefay H, Bihonegn F, Ayalew F, Haileselassie D, Kebede A, Temam G, Gidey G. International Journal of Advanced Research in Management and Social Sciences,

[4] Maria Forde, Phenomenon of Becoming a Midwife, 2014

[5] Mellish, JM \& Paton, F. 2005. An introduction to the ethos of nursing: a text for student nurses. 2nd edition. Butterworth: Heinemann.

[6] Ornella Lincetto, Seipati Mothebesoane-Anoh, Patricia Gomez, Stephen Munjanja) about_6131230_ancient-historynursing.html (accessed 3 April 2011).

[7] Opportunities for Africa's Newborns, Antenatal Care Val Wilson, Tanya McCance \& Nicole Pesa, Measuring and Benchmarking Key Performance Indicators: A Paediatric International Nursing Study (PINS)

[8] Xploring maternal and health professional beliefs about the factors that affect whether women in Saudi Arabia attend antenatal care clinic appointments 